\title{
SISTEM INFORMASI ADMINISTRASI AKADEMIK PADA BIMBINGAN BELAJAR BERBASIS WEB (STUDI KASUS DILA SAMAWA)
}

\author{
Rodianto $^{1}$, Eva Sapitri Andani² \\ ${ }^{1}$ Dosen Informatika, Universitas Teknologi Sumbawa \\ ${ }^{2}$ Mahasiswa Informatika, Universitas Teknologi Sumbawa \\ 1․odianto@uts.ac.id,,2Evasapitri751@gmail.com
}

\begin{abstract}
Abstrak
Bimbingan belajar adalah suatu bentuk kegiatan dalam proses belajar yang dilakukan oleh seseorang yang telah memiliki kemampuan lebih dalam banyak hal untuk diberikan kepada orang lain. Dila Samawa merupakan salah satu contoh pendiri bimbingan belajar di Kabupaten Sumbawa bersama Yayasan Tangan Penolong yang berpusat di Jakarta. Adapun tujuan dari penelitian ini adalah untuk membuat sistem manual yang sedang berjalan di Dila Samawa menjadi sistem yang terkomputerisasi, dengan adanya permasalahan tersebut sehingga dapat dibangun Sistem Informasi Administrasi Akademik Bimbingan Belajar Dila Samawa Berbasis Web, untuk metode perangkat lunak menggunakan waterfall, bahasa yang digunakan adalah PHP dan perancangan system menggunakan DFD (Data Flow Diagram). Sistem ini akan mempermudah admin, tutor, siswa maupun masyarakat dalam mengelolah dan mendapatkan informasi tentang administrasi akademik bimbingan belajar Dila Samawa.
\end{abstract}

Kata kunci: Sistem Administrasi Akademik Dila Samawa, Waterfall, PHP, DFD (Data Flow Diagrams)

\begin{abstract}
Tutoring is aan of activity in the learning process which is done by someone who has fulfilled the academic recietments in centain science branch. Dila Samawa is one example of founder tutoring in SumbawaYayasan Tangan Penolong based in Jakarta the research aims to transform tha paper based system at Dila Samawa into the computerized one, the system development is used waterfall, the language used is $\mathrm{PHP}$ (Hypertext Propocessor), and system design using DFD (Data Flow Diagrams). This system will make it easier for admins, tutors and students as well as the community to manage and get information abaout the administration of academic tutoring Dila Samawa.
\end{abstract}

Keyword: Academic Administration System Dila Samawa, PHP (Hypertext Propocessor), DFD (Data Flow Diagrams), 


\section{PENDAHULUAN}

\subsection{Latar Belakang}

Dila Samawa merupakan tempat bimbingan belajar yang beralamat di Jl. Kepiting Kecamatan Sumbawa Kabupaten Sumbawa.Bimbingan Dila Samawa ini adalah salah satu program Dila Samawa yang dinaungi oleh Yayasan Tangan Penolong cabang Sumbawa yang berpusat di Jakarta. Sistem yang digunakan di Dila Samawa yang sampai saat ini masih menggunakan sistem manual, salah satu contohnya adalah media promosi masih dengan cara pembagian brosur dan mengunjungi sekolah-sekolah. Calon siswa yang ingin mendaftar pada Dila Samawa harus mengurus administrasi maupun pembayaran dengan cara membuat janji untuk bertemu dengan admin. Data-data absensi maupun biodata siswa tidak tersimpan dengan rapi (belum terkomputerisasi). Dalam pengupdatean data siswa admin harus mengecek data perbulan dengan membongkar lagi berkas atau formulir yang sudah ada.

Oleh sebab itu, maka peneliti tertarik untuk membangun sebuah "Sistem Informasi Administrasi Akademik Bimbingan Belajar Berbasis Web (Studi Kasus Dila Samawa)". Aplikasi ini dibuat untuk mempermudah sistem kinerja baik siswa, admin dan tutor dalam Instansi Dila Samawa dan agar semua data dapat terkomputerisasi dengan baik.

\section{LANDASAN TEORI}

\subsection{Tinjauan Pustaka}

Tinjauan pustaka ini digunakan sebagai pembanding antara penelitian yang sudah dilakukan dan yang akan dilakukan penelitian. Penelitian tersebut di antaranya sebagai berikut:

Penelitian yang dilakukan oleh Widiyantoro (2013) yang berjudul "Pengelolaan Sistem Informasi Akademik Sms Gateway di MTS Ma'arif 7 BomoPunung kabupaten Pacitan" Tujuan penelitian ini mendiskripsikan perencanaan rancangan sistem, implementasi sistem, dan tanggapan masyarakat terhadap sekolah yang telah menerapkan sistem informasi akademik berbasis SMS gateway.

Penelitian ini memiliki persamaan dan perbedaan dengan sistem yang akan dibuat oleh penulis. Persamaannya adalah sama - sama bertujuan membangun sistem informasi yang efektif dan efisien. Sedangkan perbedaannya adalah sistem yang dibuat oleh Heri Widiyantoro berbasis SMS
Gateway. Sedangkan sistem yang akan dibuat penulis berbasis Web

Penelitian yang dilakukan oleh Permana (2014) yang berjudul "Aplikasi Sistem Informasi Akademik Berbasis Dekstop Pada SDN Pamulang Tengah Tangerang Selatan" Penelitian ini bertujuan agar dapat memberikan kemudahan pada saat proses pengolahan data murid dan guru, mempermudah dalam pengolahan nilai murid, meminimalisir kesalahan dalam pencatatan data guru dan murid, dan meningkatkan keamanan data guru dan murid sehingga keamanan data lebih terjamin.

Penelitian ini memiliki persamaan dan perbedaan dengan sistem yang akan dibuat oleh penulis. Persamaannya adalah sama - sama bertujuan membangun sistem informasi yang efektif dan efisien. Sedangkan perbedaannya adalah sistem yang dibuat oleh AristianYurian Permana berbasis dekstop menggunakan aplikasi IDE Netbeans 7.0.1 dan Xampp 1.7.7. Sedangkan sistem yang akan dibuat penulis berbasis Web.

\subsection{Dasar Teori}

Adapun dasar teori yang mendukung dalam pembuatan laporan ini sebagai berikut:

\subsubsection{Sistem Informasi}

Sistem Informasi menurut Mahatmyo (2014:6) bahwa Sistem Informasi adalah sebuah rangkaian prosedur formal dimana data dikelompokkan, diproses menjadi informasi, dan didistribusikan kepada pemakai.

Pengertian diatas dapat disimpulkan bahwa sistem informasi adalah kumpulan data yang terintegritasi dan saling melengkapi dengan menghasilkan output yang baik guna untuk memecahkan masalah dan pengambilan keputusan.

\subsubsection{Administrasi Akademik}

Risetyawan (2010:11) menyatakan bahwa administrasi akademik adalah kegiatan yang mempelajari kurikulum yang sudah ada di sekolah dengan meningkatkan ilmu pengetahuan siswa.

Penulis simpulkan bahwa administrasi akademik adalah sebuah kegiatan yang dilakukan siswa untuk mendapatkan ilmu pengetahuan serta bagaimana cara menggunakan ilmu tersebut dengan benar. 


\subsubsection{Unified Modeling Language (UML)}

Unified Modelling Languange adalah sebuah bahasa yang telah menjadi standar dalam industri untuk visualisasi, merancang dan mendokumentasikan sistem piranti lunak. UML menawarkan sebuah setandar untuk merancang model sebuah sistem (Widodo, 2011:33).

Penulis menggunakan empat UML dari tiga belas UML yang ada, karena dari ke empat UML tersebut sudah mencukupi atau memenuhi kebutuhan dari aplikasi ini. Berikut ini adalah diagram-diagram dari UML:

1. Use Case Diagram

Use case diagram merupakan permodelan dan mendeskripsikan sebuah interaksi antara satu atau lebih aktor dengan aplikasi yang akan dibuat. Dapat dikatakan use case apabila digunakan untuk mengetahui fungsi apa saja yang ada didalam aplikasi dan siapa saja yang berhak menggunakan fungsifungsi tersebut.

2. Activity Diagram

Activity diagram menggambarkan workflow (aliran kerja) atau aktivitas darisebuah sistem atau proses bisnis.

3. Sequence Diagram

Sequence diagram menggambarkan kelakuan objek pada use case dengan mendeskripsikan waktu hidup objek dan pesan yang dikirimkan dan diterima antar objek.

4. Class Diagram

Class diagram merupakan hubungan antar kelas dan penjelasan detail tiap-tiap kelas di dalam model desain dari suatu sistem, juga memperlihatkan aturan-aturan dan tanggung jawab entitas yang menentukan perilaku system.

\subsubsection{Waterfall}

Waterfall adalah pendekatan air terjun yang memakai kegiatan dan mempresentasikannya sebagai fase proses yang berbeda seperti spesifikasi persyaratan, perancangan perangkat lunak, implementasi, pengujian dan seterusnya, setelah tahap didefinisikan akan tahap diakhiri (signed off) dan pengembangan berlanjut ke tahap berikutnya (Sommerville, 2003:43)

Dapat disimpulkan bahwa waterfall adalah tahapantahapan yang dilakukan dalam membuat suatu aplikasi yang dimulai dari kebutuhan analisis, perancangan, implementasi, pengujian serta pemeliharaan.

\subsubsection{Pengujian BlackBox}

Simarmata (2010:316) berpendapat bahwa Black Box Testing mencakup beberapa pengujian yaitu, 1) pengujian fungsional meliputi fungsi sistem, perintah-perintah pengguna, manipulasi data, pencarian dan proses bisnis, pengguna layar dan integrasi, 2) pengujian tegangan yang menciptakan sebuah lingkungan yang berkaitan dengan kualitas aplikasi, 3) pengujian beban untuk mengetahui apakah aplikasi gagal/kinerjanya menurun.

Dari penjelasan diatas, maka dapat disimpulkan bahwa Black Box Testing adalah suatu metode yang berfungsi untuk menguji semua fungsi kebutuhan software dari menu satu dengan menu yang lain.

\section{METODOLOGI PENELITIAN}

\subsection{Metode Penelitian}

Tahap-tahap yang dilakukan dalam pengumpulan data untuk merancang dan membangun sistem informasi ini dapat digambarkan pada bagan alur sebagai berikut:

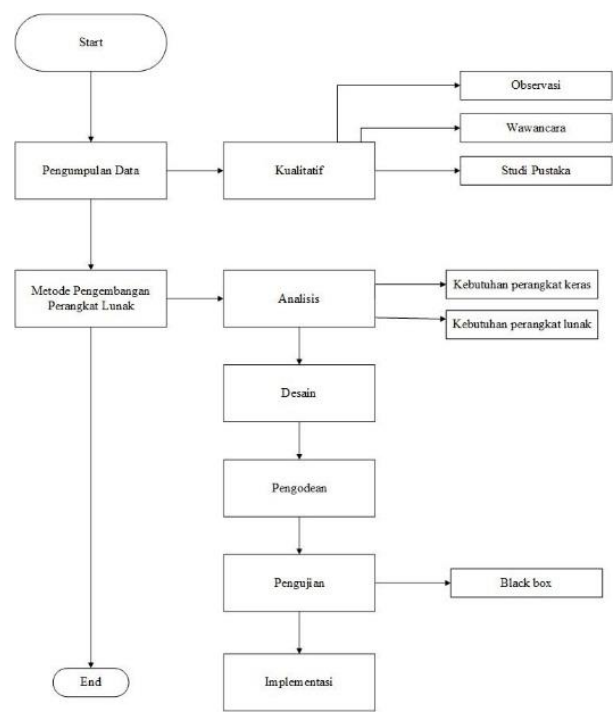

Gambar 3.1 Metode Penelitian

\subsection{Metode Pengumpulan Data}

Metode pengumpulan data adalah metode yang digunakan untuk mengumpulkan data yang dibutuhkan dalam penelitian, metode yang digunakan adalah sebagai berikut :

a. Observasi 
Observasi dilakukan untuk mengumpulkan data dengan cara terjun langsung ke lapangan atau lokasi, data yang dibutuhkan dalam penelitian skripsi ini berupa data siswa, data tutor, persyaratan bimbingan belajar.

b. Wawancara

Dalam wawancara ini, peneliti mewawancarai Pimpinan Dila Samawa Bapak Jhon Yaved dan Manager nya Ibu Fanly Christina untuk mendapatkan informasi yang faktual tentang Dila Samawa. Beberapa pertanyaan yang diberikan kepada narasumber sudah ada dalam halaman lampiran di bawah.

c. Studi Pustaka

Peneliti yang dilakukan dengan cara membaca dan mempelajari buku-buku yang berhubungan dengan masalah yang akan diteliti sebagai tinjauan pustaka. Dalam penelitian ini, referensi yang digunakan berupa jurnal serta penelusuran melalui internet.

\subsection{Metode Pengembangan Perangkat Lunak}

Prosedur pengembangan yang digunakan pada sistem informasi bimbingan belajar pada Dila Samawa ini yaitu menggunakan metode waterfall. Metode waterfall merupakan pengerjaan dari suatu sistem yang dilakukan secara berurutan atau secara linier. Disebut dengan waterfall karena tahap demi tahap yang dilalui harus menunggu tahap sebelumnya selesai.

Adapun menurut (Pressman dan Roger, 2012) metode waterfall mempunyai tahapan-tahapan sebagai berikut :

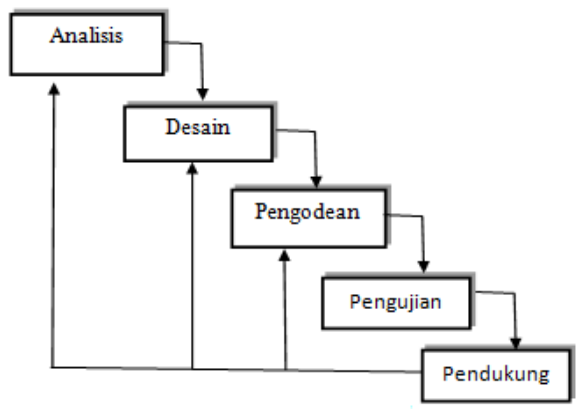

Gambar 3.2 Metode Waterfall

\subsection{Alat Dan Bahan Penelitian}

Alat penelitian yang digunakan dibagi menjadi dua yaitu komponen perangkat keras, perangkat lunak, dan kebutuhan data sebagai pendukung penelitian yang dilakukan, alat ini yang akan dijadikan sebagai alat pengolahan data dan pembuatan sistem yang akan dirancang.

\section{HASIL DAN PEMBAHASAN}

Adapun penerapan dari hasil metode waterfall yang telah diterapkan sampai dengan implementasi sistem. Pada penelitian ini dibagi atas pembahasan hasil analisis dan perancangan sistem informasi.

\subsection{Use Case Diagram}

Berikut ini adalah use case diagram dari sistem Informasi Administrasi Akademik Bimbingan Belajar Berbasis Web Dila Samawa dibagi menjadi 3 aktor yaitu admin, tutor dan siswa:

1. Use case diagram untuk aktor admin

Berikut ini merupakan usecase diagram untuk bagian admin. Yang menjelaskan hubungan aktor dengan aktifitas-aktifitas pada sistem informasi berbasis web.

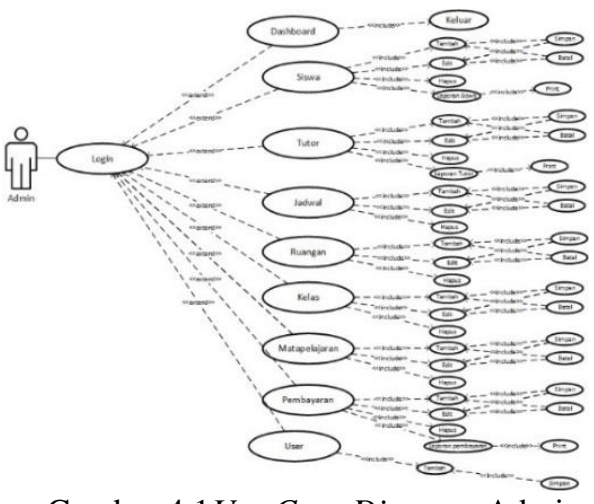

Gambar 4.1Use Case Diagram Admin

2. Usecase diagram untuk tutor

Berikut ini merupakan usecase diagram untuk bagian tutor. Yang menjelaskan hubungan aktor dengan aktifitas-aktifitas pada sistem informasi:

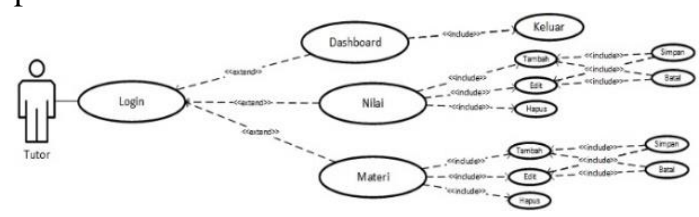

Gambar 4.2 Use Case Diagram Tutor

3. Usecase diagram untuk siswa

Berikut ini merupakan usecase diagram untuk bagian siswa. Yang menjelaskan 
hubungan aktor dengan aktifitas-aktifitas pada sistem informasi:

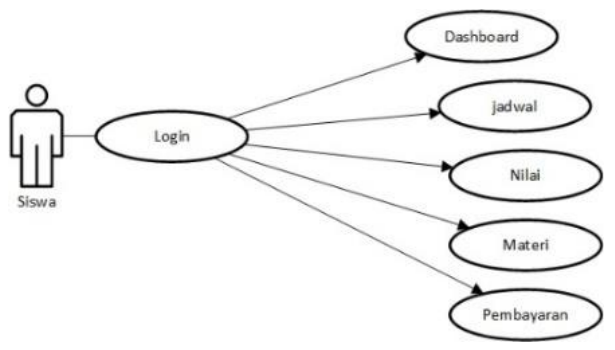

Gambar 4.3 Use Case Diagram Siswa

\subsection{Activity Diagram}

Setiap bagian memiliki beberapa activity diagram yang berfungsi untuk menggambarkan alur proses dalam sistem aplikasi. Berikut adalah Activity Diagram dalam sistem yang ingin dibangun:

1. Activity diagramhalaman utama admin Gambar dari activity diagram adalah sebagai berikut:

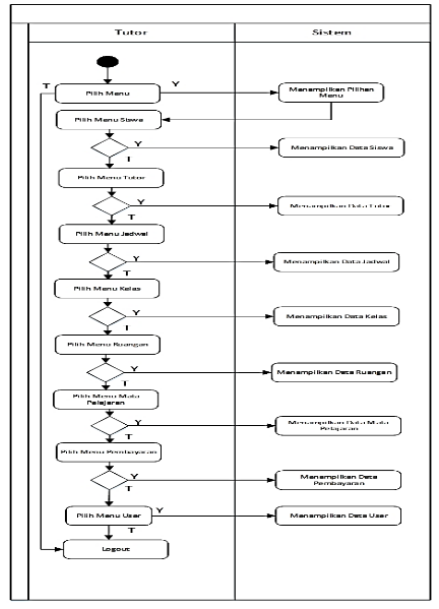

Gambar 4.4 Activity Diagram Admin

Pada Activity Diagram diatas, dapat dijelaskan bahwa admin akan masuk kehalaman utama dengan proses login terlebih dahulu, kemudian system akan menampilkan halaman utama admin yang dimana halaman tersebut terdapat menu-menu seperti data siswa, data tutor, data kelas, data ruangan, data jadwal, data mata pelajaran, data pembayaran, dan data user yang bisa dipilih agar admin dapat melakukan aktifitas system.

2. Activity diagramadmin kelola data siswa Adapun activity diagram admin kelola data siswa dapat digambarkan sebagai berikut:

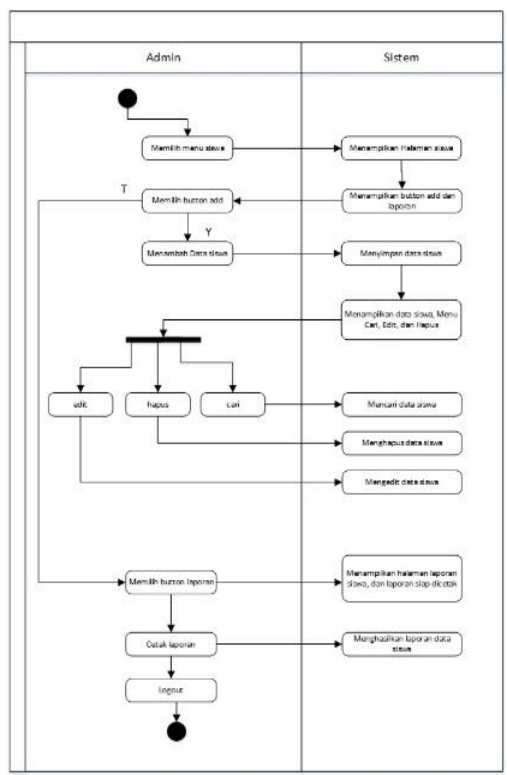

Gambar 4.5Activity Diagram Kelola Data Siswa

Dari gambar diatas, dapat dijelaskan bahwa admin memilih menu siswa dan system akan menampilkan halaman siswa. Jika admin ingin menambahkan data siswa maka dapat memilih butoon add pada halaman siswa dan system akan menampilkan data siswa yang sudah ditambah dan menampilkan menu cari, edit dan hapus. Dari ketiga menu tersebut admin akan memilih salah satu aktifitasnya ingin mengedit, menghapus atau mencari data. Jika admin ingin keluar dari halaman dapat memilih logout.

3. Activity Diagram tutor kelola data nilai

Berikut adalah gambar dari activity diagram tutor kelola data nilai:

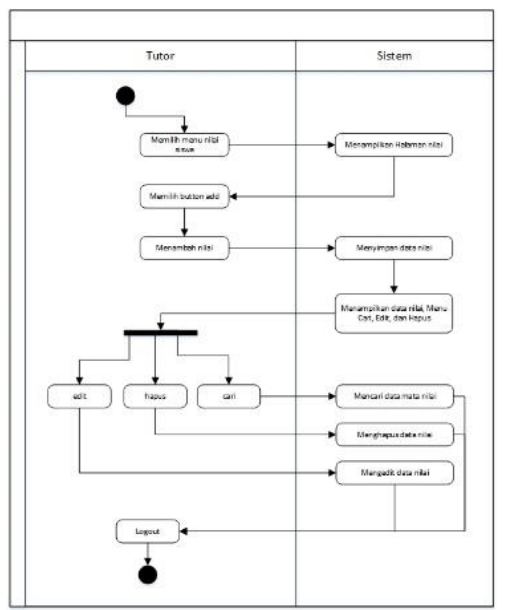

Gambar 4.6 Activity Diagram Kelola Nilai 
Pada gambar di atas dapat dijelaskan bahwa tutor akan mengelola nilai siswa dengan cara memilih menu nilai pada halaman utama, kemudian system akan menampilkan halaman nilai. Jika tutor akan menambahkan data nilai siswa, tutor dapat memilih button siswa sedangkan system menyimpan data nya dan menampilkan kembali menu edit, hapus dan cari data yang berguna untuk tutor melakukan aktifitas data yang ingin dilakukan.

4. Activity diagram siswa lihat data jadwal Adapun gambar activity diagram siswa melihat data jadwal sebagai berikut:

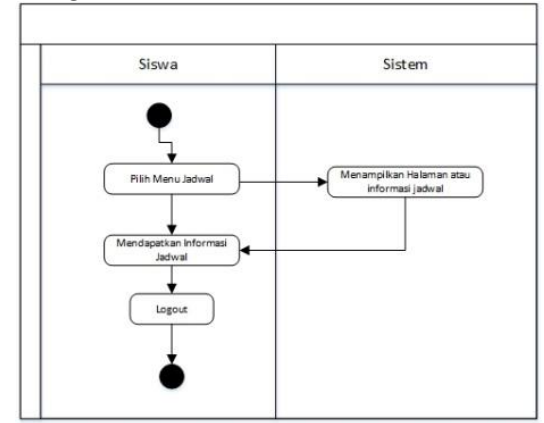

Gambar 4.7 Activity Diagram Siswa melihat Data Jadwal

Pada gambar diatas menjelaskan bahwa siswa hanya dapat melihat informasi jadwal yang di tampilkan oleh system dan dikelolah oleh admin. Siswa dapat keluar dari halaman setelah memilih menu logout pada halaman.

\subsection{Sequence Diagram}

Sequence diagram digunakan untuk menggambarkan interaksi antar objek-objek yang ada. Berikut dibawah ini adalah sequence diagram pada perancangan sistem yang di usulkan:

1. Sequence diagramHalaman utama admin

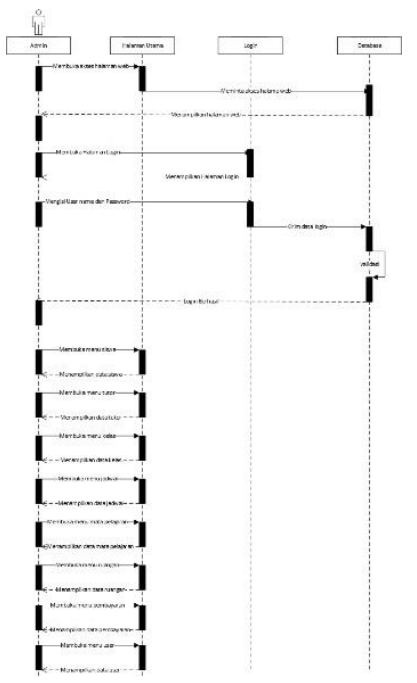

Gambar 4.8Sequence Diagram Admin

Proses dimulai pada saat admin membuka dan mengakses web. Adapun prose yang dilakukan pertama kali oleh admin adalah proses login dengan menginput user name dan password. Kemudian system akan menampilkan menu awal seperti menu suswa, tutor, kelas, pembayaran dan user.

2. Sequence diagram halaman tutor kelola nilai

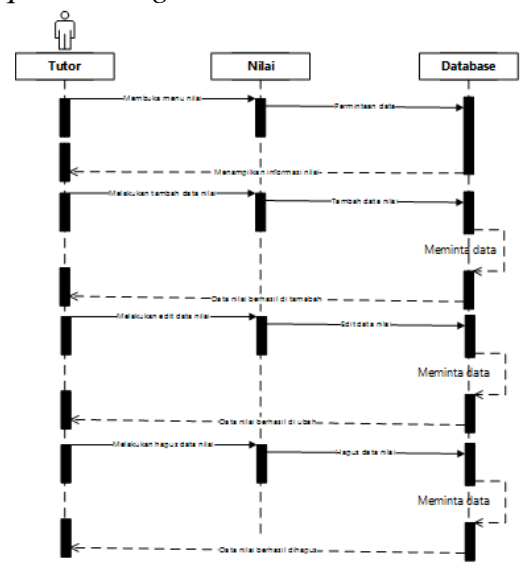

Gambar 4.9SequenceDiagram Kelola Nilai

Pada proses ini, tutor akan mengelola nilai dengan membuka menu nilai. Jika tutor ingin melakukan aktivitas seperti add, edit dan hapus, maka database akan mengirimkan hasil dari aktifitas tersebut. 
3. Sequence Diagram halaman admin kelola data

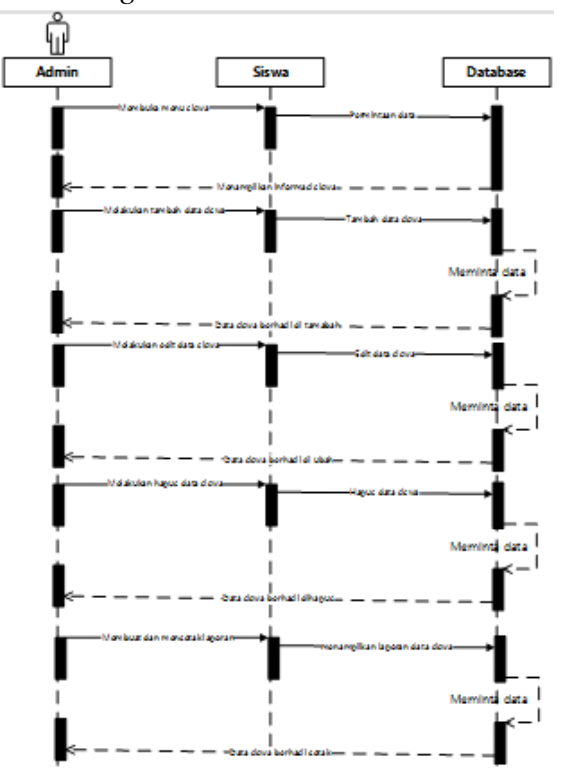

Gambar 4.10Sequence Diagram Admin

Kelola Data Siswa

Pada proses ini, admin akan mengelola data siswa dengan membuka menu siswa. Jika admin ingin melakukan aktivitas seperti add, edit, hapus, dan cetak data maka database akan mengirimkan hasil dari aktifitas tersebut.

\subsubsection{Class Diagram}

Class diagram menunjukan interaksi antar kelas dan aplikasi serta garis yang dihubungkan antar kelas menunjukan hubungan komunikasi antara class diagram. Berikut dibawah ini merupakan class diagram Sistem Informasi Administrasi Akademik Pada Bimbingan Belajar Berbasis Web Kasus Dila Samawa:

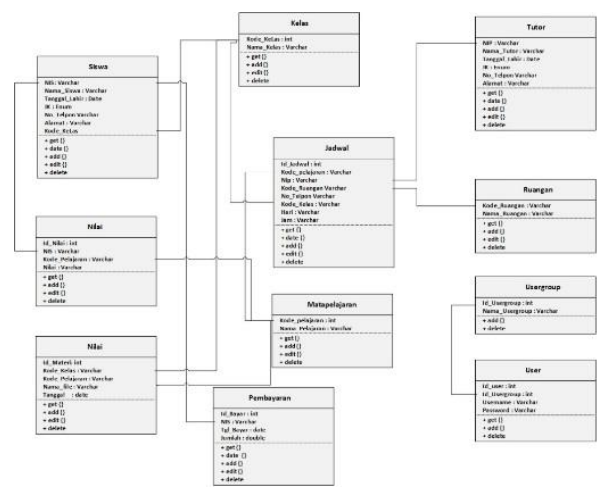

Gambar 4.11 Class Diagram

\subsection{Perancangan Interface}

Adapun rancangan tampilan pada sistem ini adalah sebagai berikut:

\section{Dashboard Admin}

Adapun tampilan dashboard admin adalah sebagai berikut:

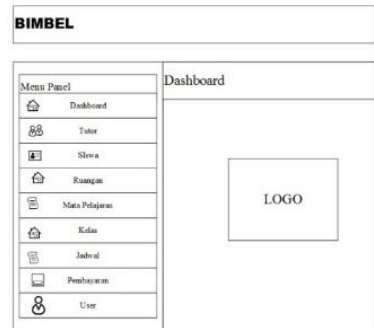

Gambar 4.12Dashboard Admin

Pada halaman dashboard admin terdapat beberapa menu pilihan seperti data guru, data siswa, data ruangan, data mata pelajaran, data kelas, data jadwal, data pembayaran, data user.

2. Rancangan admin kelola data siswa Berikut adalah gambar dari rancangan tampilan dashboard siswa:

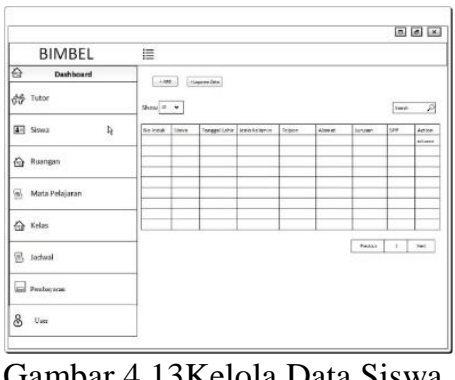

Di halaman siswa pada login admin berfungsi untuk mengelola data siswa, ada beberapa menu yang terdapat pada halaman ini seperti menambahkan data siswa, membuat laporan data siswa, menu pencarian dan menu action yang digunakan untuk mengedit dan delete data jika ada perubahan pada data siswa.

3. Tutor kelola data

Adapun tampilan dashboard admin adalah sebagai berikut: 


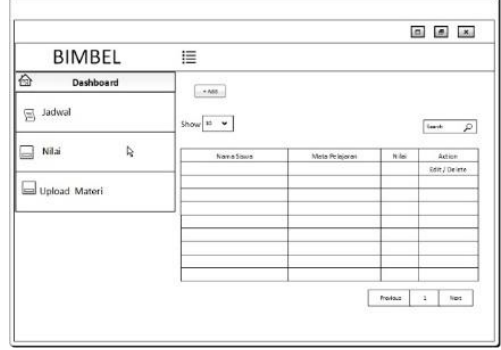

Gambar 4.14 Kelola Nilai

Pada halaman nilai, tutor dapat mengelola nilai dengan menginput nama siswa, mata pelajaran dan nilai. Jika tutor ingin menambahkan data, edit atau hapus, maka tutor dapat memiilih menu action dan add.

\subsection{Implementasi Interface}

Setelah melakukan perancangan sistem antar muka, langkah selanjutnya adalah mengimplementasinya. Adapun tampilan dari sistem ini adalah sebagai berikut:

1. Tampilan halaman utama web

BIMBEL DILASAMAWA

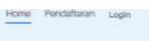

*itions

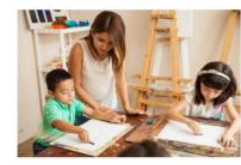

VISI-MISI

was

Gambar 4.15 Tampilan Halaman utama web

Tampilan Halaman utama web

Pada halaman ini berfungsi sebagai salah satu media promosi, dimana calon siswa maupun masyarakat luar bisa mengetahui semua informasi mengenai Bimbingan Dila Samawa secara umum. Terdapat tiga menu yang ada di halaman utama web ini seperti home, halaman pendaftaran yang berfungsi agar calon siswa bisa mendaftar, dan menu login berfungsi agar siswa mendapatkan informasi mengenai jadwal, nilai, dan materi.

\section{Tampilan login}

Adapun tampilan Login User sebagai berikut:

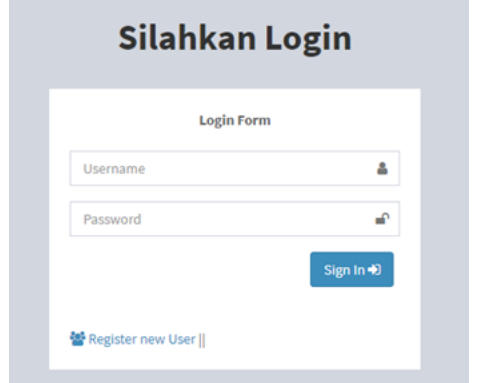

Gambar 4.16 Tampilan Halaman Login

Pada halaman ini admin, siswa maupun tutor diminta untuk memasukkan username dan password. Halaman login ini menggunakan multi user jadi program akan secara otomatis membedakan akses user.

3. Tampilan halaman utama admin Berikut tampilan halaman utama admin:

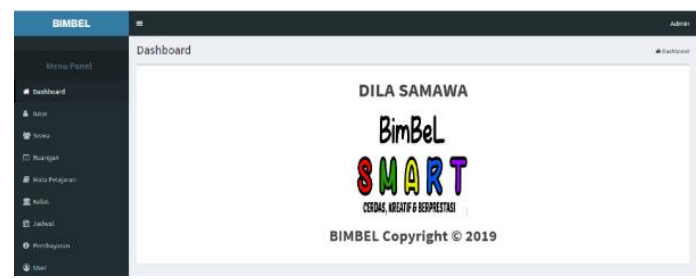

Gambar 4.17 Tampilan Halaman Admin

Pada menu dashboard admin ini terdapat tampilan untuk mengetahui dan mengelolah data tutor, data siswa, data ruangan, data mata pelajaran, data kelas, data jadwal, data pembayaran dan data user. Serta terdapat logo bimbingan belajar Dila Samawa.

4. Tampilan halaman admin kelola data Berikut adalah gambar dari halaman admin input data, hasil dari penginputan data dan laporan data:

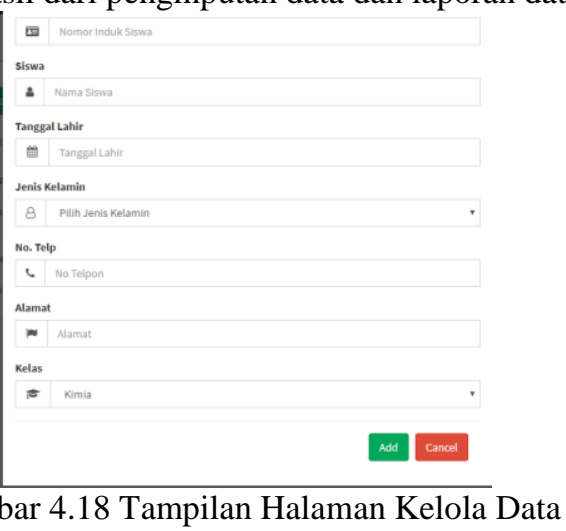

Gambar 4.18 Tampilan Halaman Kelola Data

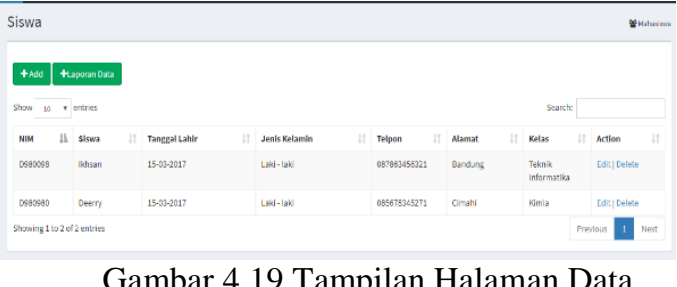

Gambar 4.19 Tampilan Halaman Data 


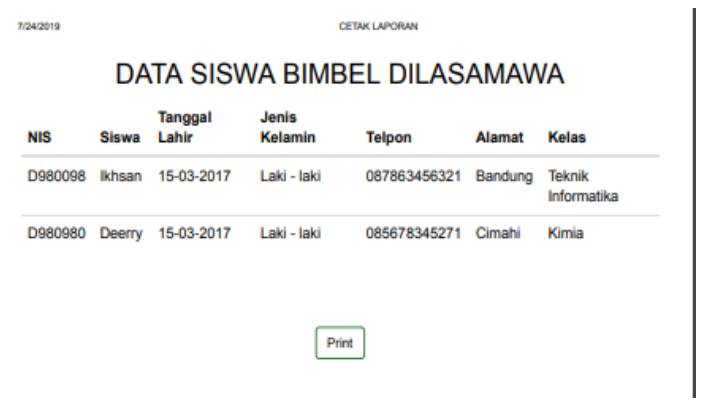

Gambar 4.20 Tampilan Halaman Laporan Data

Pada gambar diatas menjelaskan bahwa admin mengelola data siswa yang dimana admin dapat menambahkan data dengan memilih button add dan akan muncul tampilan data yang sudah diinput, kemudian jika admin ingin membuat laporan, admin dapat memilih button laporan dan laporan siap dicetak.

\subsection{Pengujian Sistem}

Pengujian sistem yang penulis buat menggunakan blackbox testing untuk pengujian proses input dan outputnya saja. Berikut penulis tampilkan hasil

pengujian:

a. Login user (Admin, Tutor, Siswa)

Adapun pengujian login adalah sebagai berikut:

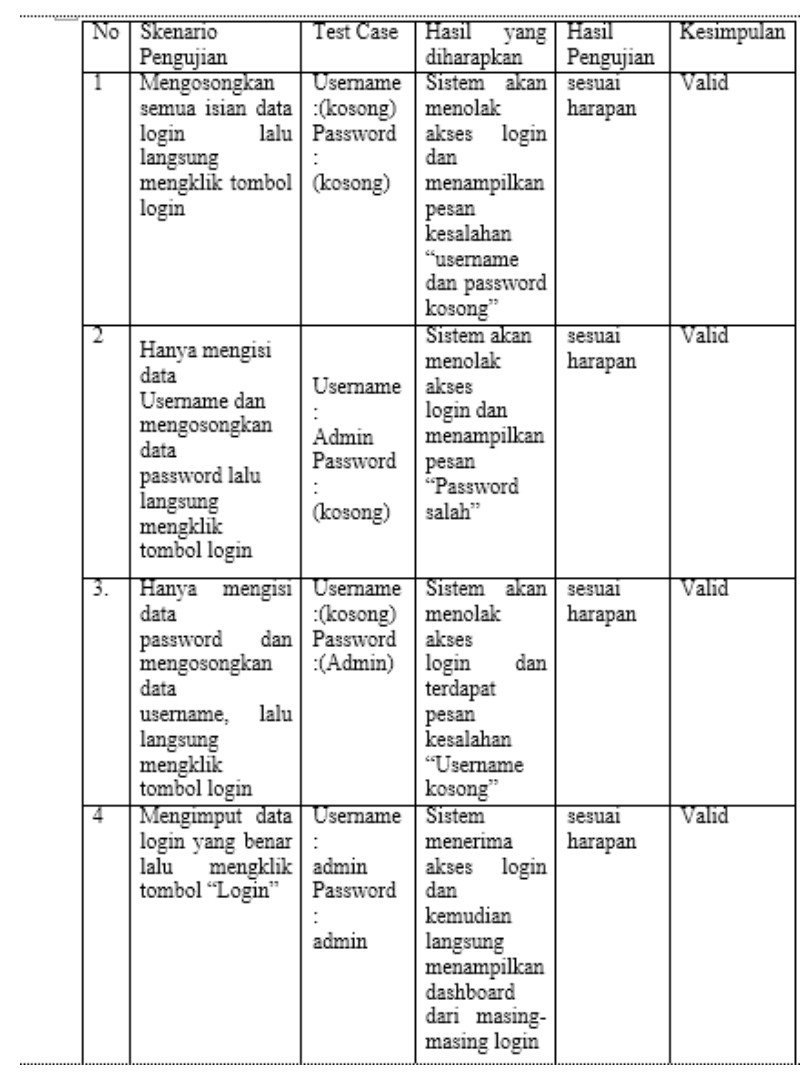

Gambar 4.22 Gambar Pengujian Login

b. Pengujian Sistem Input Data

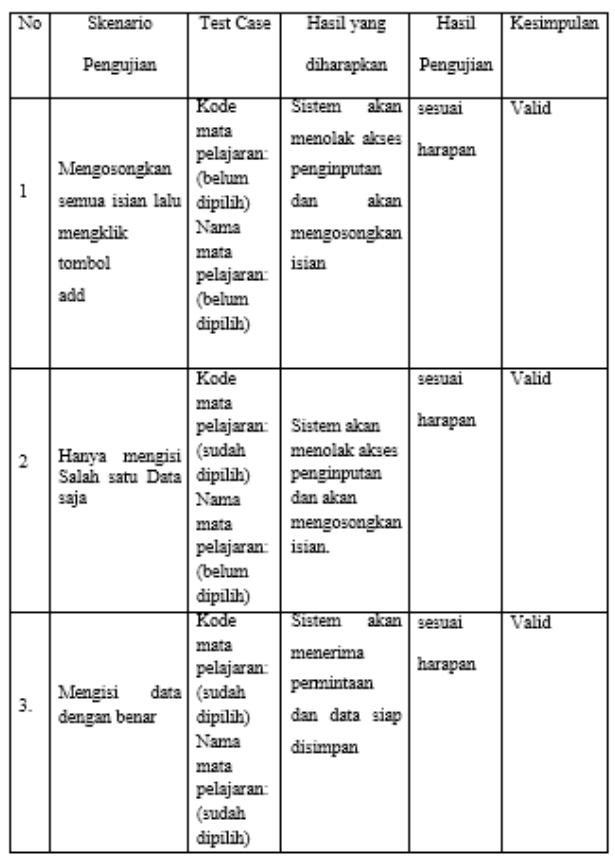

Gambar 4.23 Pengujian Input Data 
c. Pengujian system pencarian data Adapun pengujian system pencarian data sebagai berikut :

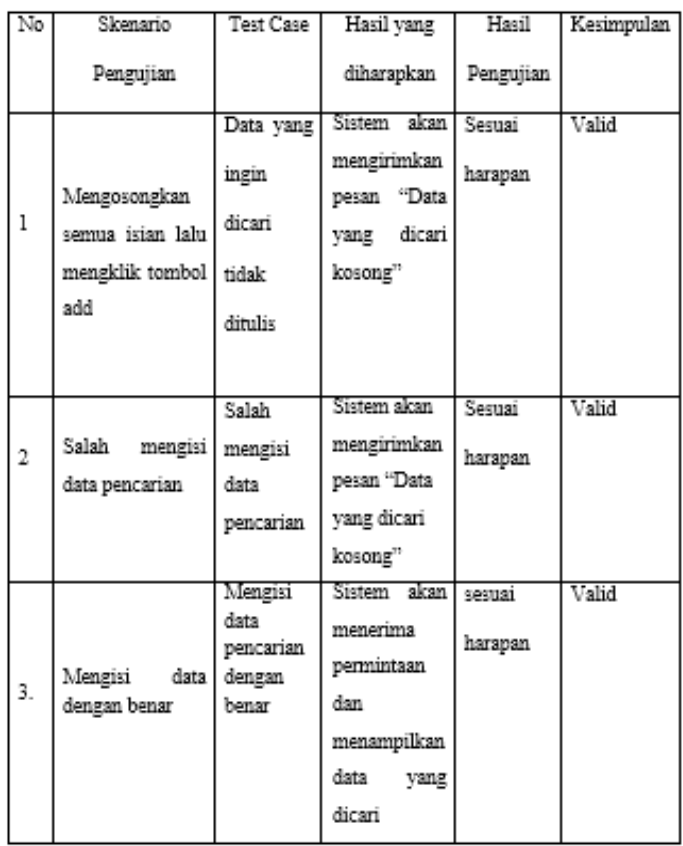

Gambar 4.23 Pengujian Pencarian Data

\section{PENUTUP}

\subsection{Kesimpulan}

Berdasarkan hasil penelitian ini, ada beberapa kesimpulan yang dapat diambil :

1. Peneliti sudah berhasil membangun aplikasi dengan menggunakkan Bahasa pemrograman Hypertext Preprocessor (PHP) dengan metode perangkat lunak waterfall dan pengujian sistem menggunakan BlackBox.

2. Memudahkan seluruh user atau pemakai dalam mengakses informasi mengenai Dila Samawa terutama admin dan tutor dalam instansi Dila Samawa.

\subsection{Saran}

Aplikasi yang telah dibuat masih jauh dari kesempurnaan. Adapun saran terhadap Aplikasi yang telah dibuat adalah sebagai berikut:

1. Diperlukan sentuhan design agar aplikasi terlihat lebih bagus dan menarik.

2. Lebih lengkap jika ditambahkan menumenu laporan, seperti laporan keuangan (keuangan pemasukan, pengeluaran), laporan keuangan gaji, dan uang kas, agar memudahkan admin dalam mengelola data keuangan.

3. Sistem informasi diharapkan dapat berfugsi seperti aplikasi secara umum yang bersifat online, agar dapat diterapkan langsung pada Dila Samawa.

\section{DAFTAR PUSTAKA}

[1] Mahatmyo, Atyanto. (2014). Sistem Informasi Akuntansi: Suatu Pengantar. Yogyakarta: Deepublish.

[2] Permana, Aristia Yurian. (2014). Aplikasi Sistem Informasi Akademik Berbasis Desktop pada SDN Pamulang Tengah Tangerang Selatan. Skripsi. Universitas Pamulang.

[3] Pressman, Roger S. 2012. Rekayasa Perangkat Lunak - Buku Satu, Pendekatan Praktisi (Edisi 7). Yogyakarta: Andi.

[4] Simarmata, Janner. (2010). Rekayasa Perangkat Lunak. Yogyakarta. Andi.

[5] Sommerville, Ian. (2003). Software Engineering (Rekayasa Perangkat Lunak). Jakarta: Erlangga.

[6] Widiantoro, Heri. (2013). Pengelolaan Sistem Informasi Akademik Sms Gateway di MTS Ma'arif 7 BomoPunung kabupaten Pacitan. Tesis. Universitas Muhammadiyah Surakarta

[7] Widodo. Prabowo.P, Dkk. (2011). "Pemodelan sistem berorientasi objek dengan UML". Yogyakrta: Graha Ilmu 